\title{
TRANS-2-HEXENAL /N-TRIDECANE COMBINATION: A NATURAL FUMIGANT OF THE DEFENSIVE SECRETION OF CORIDIUS JANUS (HEMIPTERA: PENTATOMIDAE)
}

\author{
NEELAKANTHI E. GUNAWARDENA AND H.M.W.K.B. HERATH \\ Department of Chemistry, University of Kelaniya, Kelaniya.
}

(Date of receipt $\quad: 08$ October 1990)
(Date of acceptance $:$ 25 June 1992)

\begin{abstract}
The defensive secretion of Coridius janus, Fabricius (Hemiptera: Pentatomidae) was analysed by combined gas chromatography - mass spectrometry (GC-MS). Trans-2 hexenal and n-tridecane were found to be the major volatiles consisting of an average of $90 \%$, while dodecane and 4-oxo-trans-2-hexenal were present in small quantities together with nineteen other trace compounds. Laboratory toxicity assay showed this secretion to possess insecticidal activity by fumigant action. In a toxicity assay for three selected test insects.Anoplolepis longipes, Sitotroga cerealella and Culex quinquefasciatus LCso values of $0.197,0.003$ and $0.0002 \mathrm{ppm}$ respectively were obtained. Column fractionation of this defensive secretion followed by bioassay of the fractions demonstrated higher toxicity of $t-2$ hexenal $/ n$-tridecane combinations compared to those of single constitutents. This was further proved by the toxicity tests with different combinations of the above two compounds and a particular combination with the ratio of $\boldsymbol{t}$-2-hexenal; $\mathbf{n}$-tridecane $=$ $60: 40(\mathrm{w} / \mathrm{w})$ respectively was shown to possess highest activity towards all three test insects.
\end{abstract}

Key words: 1-2-Hexenal/n-Tridecane, fumigant, defensive secretion, Coridius janus, hemiptera.

\section{INTRODUCTION}

Volatile constituents of the defensive secretions of Hemipterans have been subjected to thorough study in the past years. GC-MS analyses have revealed that these secretions possess a wide variety of compounds amongst which unsaturated and saturated aldehydes, ketones, alcohols, esters and hydrocarbons are prominent. The chemistry of a large number of defensive compounds and their distribution among Hemipteran species have been well documented. ${ }^{1-3}$ Despite extensive chemical analyses less efforts have been devoted to research on biological aspects of the defensive secretion of Hemipterans compared to those of social insects. ${ }^{4-6}$ Among research on the functional role of defensive secretions however, alarm pheromone activity 7,8 and repellent properties have been studied ${ }^{9,10}$ comparatively to a greater extent while insecticidal properties still remain at preliminary stages. ${ }^{11,12}$. Proper investigations on the strength of insecticidal activity compared to those of the commercial insecticides have never been carried out despite the fact that this information could be of immense value to man in terms of his search for harmless insecticides. 
Coridius janus is a pentatomid bug found in sweet pumpkin (Cucurbitaceae) fields in the dry zone of Sri Lanka. This insect possesses a remarkable ability to survive among predators owing to an odoriferous defensive secretion. When the insect is disturbed it ejects a light yellow coloured secretion as a fine spray for distances of several inches. This secretion was found to be stored in a large red sac placed in the ventral side of the abdomen. Preliminary investigations revealed that this secretion possesses fumes that could repel and kill insects. ${ }^{13}$ Our study involved (1) demonstration of the toxicity of fumes of this secretion to three different test insects viz. Anoplolepis longipes (Fomicidae), a natural enemy of $C$. janus and two pests of man, Sitotroga cerealella (Gelechiidae), a stored product pest for which fumigants are of importance and Culex quinquefasciatus (Culicidae), vector of urban filariasis in Sri Lanka, for which spraying toxicants are of value, (2). comparison of toxicity with those of commercial insecticides that are commercially used for the above pests, (3) chemical characterization of the major volatiles, and (4) identification of chemicals or chemical combinations responsible for toxicity.

\section{METHODS AND MATERIALS}

\section{Chemicals}

Trans-2-hexenal, n-tridecane and pentane (Aldrich Chemicals, UK) found to be 99.9\% pure by gas chromatography. Liquid paraffin (BDH, UK) and samples of Malathion and Elsane (Penthoate) obtained from (Environmental Protection Agency Health Effects Laboratory, Research Triangle Park, NC, USA) were used in the study.

\section{Preparation of samples for bioassay:}

Fresh defensive secretion: Adults of $C$. janus were collected from their natural habitat, the sweet pumpkin fields in the Kurunegala district, only a few days prior to experiments. Individual $C$. janus in a small light glass vessel of known weight were subjected to persistent assault on the thorax and head until the secretion was ejected. Immediately after this, the insects were removed from the respective vessels and the vessels were closed and weighed. These samples were cooled and handled carefully thereafter so as not to loose volatiles. The composition of each sample was checked by GLC and those having equal or nearly equal compositions to that of the representative sample (Table 4) were used in the bioassay for toxicity. This was to avoid possible effects in the end result due to variable ratios of 2-hexenal to n-tridecane in individual defensive secretions. Finally the defensive secretion was diluted with paraffin oil 1:100 ratio respectively and appropriate doses (Table 1) were measured into small glass vials which were used subsequently in the bioassay. 
Table 1: The amounts of toxicants evaporated into the fumigating chamber

\begin{tabular}{|c|c|c|c|c|c|c|c|c|c|c|c|}
\hline \multirow{3}{*}{ Toxicant } & \multicolumn{11}{|c|}{ Amounts used (mg\#) } \\
\hline & \multicolumn{3}{|c|}{ A. longipes } & \multicolumn{4}{|c|}{ C. quinquefasciatus } & \multicolumn{4}{|c|}{ S. cerealella } \\
\hline & I & II & III & I & II & III & IV & I & II & III & IV \\
\hline $\begin{array}{l}\text { Fresh } \\
\text { defensive } \\
\text { secretion. }\end{array}$ & 1.0 & 2.0 & 3.0 & 0.005 & 0.01 & 0.05 & 0.1 & 0.005 & 0.01 & 0.05 & 0.1 \\
\hline $\begin{array}{l}t-2 \text {-hex. and } \\
\text { n-tridec. }{ }^{*}\end{array}$ & 3.0 & 6.0 & 8.0 & 0.8 & 1.0 & 5.0 & - & 0.8 & 1.0 & 5.0 & - \\
\hline $\begin{array}{l}\text { Malathion } \\
\times 10^{-4}\end{array}$ & 1.0 & 50 & 100 & 0.5 & 1.0 & 30 & - & 0.5 & 1.0 & 70 & - \\
\hline
\end{tabular}

\# All experiments were carried out in $10 \mathrm{~L}$ fumigating chamber and for the calculation of Lethal Concentration (LC 50 ), a complete evaporation of toxicants into the jar was ensured by weighing empty carriers before and after the experiments. Three concentrations of each test substance was assayed for LC 50 value except in the case of defensive secretion against $C$. quinquefasciatus and $S$.cereallellawhere four concentrations were assayed.

The ratio between these compounds were $60: 40(\mathrm{w} / \mathrm{w})$ respectively. 
Column fractions: Column fractions having similar GLC compositions were combined, to give 6 combined fractions. These 6 fractions were concentrated under reduced pressure ( 15 Torr) with a bath temperature of $20^{\circ} \mathrm{C}$. From each concentrated fraction $0.50 \mathrm{mg}$ were weighed into small glass vials and were assayed for toxicity using $A$. longipes as the test insect.

Synthetic chemicals: Neat liquids of $t$-2-hexenal and $n$-tridecane were separately dispensed from calibrated micropipettes into small glass vials. In the case of the above chemical combinations, neat liquids of 2-hexenal and $n$-tridecane in desired ratios $(w / w)$ were first mixed thoroughly until a single phase was obtained and then appropriate doses (Table 2) were weighed out into small glass vials.

Table 2: Amounts of $t$-2-hexenal and n-tridecane used in the preparation of combinations

\begin{tabular}{lllllll}
\hline Test Insect & & \multicolumn{5}{c}{ Amounts used (mg)* } \\
\hline & $\begin{array}{l}\text { Pure } \\
\text { t-2-hex. }\end{array}$ & $t$-2-hex. & n-tridec. & combination & $\begin{array}{l}\text { Pure } \\
\text { n-tridec. }\end{array}$ \\
& $100: 00$ & $80: 20$ & $60: 40$ & $40: 60$ & $20: 80$ & $00: 100$ \\
$(\mathrm{w} / \mathrm{w})$ & & & & & & \\
& $12.0: 00$ & $9.6: 2.4$ & $7.2: 4.8$ & $4.8: 7.2$ & $2.4: 9.6$ & $00: 12.0$ \\
A longipes & $3.0: 00$ & $2.4: 0.6$ & $1.8: 1.2$ & $1.2: 1.8$ & $0.6: 2.4$ & $00: 3.0$ \\
S.cerealella & $2.6: 00$ & $2.0: 0.5$ & $1.5: 1.0$ & $1.0: 1.5$ & $0.5: 2.0$ & $00: 2.6$ \\
C. quinquefasciatus & & & & & & \\
\hline
\end{tabular}

* Each combination was assayed in three replicates

Appropriate amounts of Malathion and Elsane could only be measured in the form of solutions. Paraffin oil was not found to be a suitable solvent due to insolubility of the above toxicants in it. Thus pentane solutions were made and appropriate doses of Malathion and Elsane were dispensed onto filter paper strips and the pentane was allowed to evaporate. Preferential evaporation of the solvent was possible due to the non volatile nature of the toxicants.

Chemical analysis: GLC was carried out on a Shimadzu GC-6A instrument fitted with Flame Ionization Detector (FID), a $\mathrm{He}$ flow of $30 \mathrm{ml} / \mathrm{min}$. temperature programmes of $40 \longrightarrow 250^{\circ} \mathrm{C}$ at $8^{\circ} \mathrm{C} / \mathrm{min} ., 240^{\circ} \mathrm{C}$ detector and injector temperature, glass columns $(0.25 \mathrm{~m}$ ID $\times 30 \mathrm{M}$ : SPB 1 stationary phase). Relative ratios of components were calculated as percentages of the sum total of peak areas. GC-MS was carried out on a Shimadzu GC-MS QP 1000A, EI mode at $70 \mathrm{eV}$, splitless injection and under similar GLC conditions mentioned above. 
Column fractionation: Column fractionation of the natural defensive secretion (2.0g) was carried out on a silica gel column $(70 \mathrm{~g}$, Merck, $35-70 \mathrm{mesh}$, glass coloumn, $2 \mathrm{~cm}$ ID $X 60 \mathrm{~cm}$ length) eluting with pure petroleum ether followed by mixtures of petroleum ether/methylene chloride ( $5 \%$ increments of polarity, $70 \mathrm{ml}$ solutions) running upto pure methylene chloride and finally with mixtures of methylene chloride/methanol (5\% increments of polarity, $70 \mathrm{ml}$ solutions) running upto pure methanol. Effluent was collected in $50 \mathrm{ml}$ fractions and was analysed by GLC. Those fractions containing similar GLC compositions were combined and concentrated and samples were prepared for bioassay as described previously.

Table 3: $\quad \mathbf{L C}_{50}$ values for the defensive secretion of $C$. janus, Malathion, Elsane and t-2-hehxenal:n-tridecane mixture $(60: 40, w / w)$ for A. longipes, C. quinquefasciatus and S. cerealella

\begin{tabular}{lcccc}
\hline Insect & \multicolumn{4}{l}{$\mathrm{LC}_{50}$ values of the four toxicants $(\mathrm{ppm}) \#}$. \\
\hline & $\begin{array}{l}\text { C. janus } \\
\text { Secretion } \\
\mathrm{x} 10^{-2}\end{array}$ & $\begin{array}{l}\text { t-2 hex: } \\
\text { tridecane } \\
(60: 40, \mathrm{w} / \mathrm{w})\end{array}$ & $\begin{array}{l}\text { Malathion } \\
\mathrm{x} 10^{-4}\end{array}$ & $\begin{array}{l}\text { Elsane } \\
\mathrm{x} 10^{-4}\end{array}$ \\
\hline A. longipes & 19 & 0.62 & 3.9 & \\
& $(22-17)$ & $(0.71-0.53)$ & $(4.5-3.3)$ & $(5.5-5.0)$ \\
C. quinquefasciatus & 0.21 & 0.13 & 0.26 & 2.8 \\
& $(0.22-0.20)$ & $(0.23-0.30)$ & $(0.38-0.13)$ & $(3.3-2.2)$ \\
S.cerealella & 0.30 & 0.15 & 0.34 & 0.17 \\
& $(0.44-0.14)$ & $(0.25-0.05)$ & $(0.46-0.21)$ & $(0.18-0.15)$ \\
& & & & \\
\hline
\end{tabular}

* All values represent mean LC. $50 \mathrm{ppm}$ of three replicates and confidence intervals (CI) at $95 \%$ in the parentheses

\# Appropriate doses of above toxicants (sec Table 1) being allowed to evaporate into a volume of $10 \mathrm{~L}$ were exposed to test insects (20-30) for a period of $24 \mathrm{~h}$.

Bioassay for toxicity by fumigant action: Test insects, $A$. longipes, S.cerealella and females of $C$. quinquefasciatus were collected from their respective natural habitats a few hours prior to experiments and were fed with sugar solutions, avian blood and paddy grains respectively, before being subjected to bioassay. Batches consisting of 20-30 insects were confined to glass jars of volume $10 \mathrm{~L}$ and were allowed to acclimate to the new environment for $15 \mathrm{~min}$. Test compounds in their most suitable forms, for example, fresh defensive secretion in a medium of paraffin oil, $t$-2-hexenal/ $\mathbf{n}$-tridecane mixtures without a carrier as neat liquids and Malathion and Elsane being absorbed on to filter paper strips, were slowly introduced into the fumigating jar from a small opening at the bottom and the contents were allowed to evaporate into the jar. In 
cases where carriers were used, viz. filter paper strips or paraffin oil, these materials were slightly warmed with a drier from outside the jar in order to facilitate complete evaporation of toxicants from the carrier. Carrier/glass vials used to transfer toxicants into fumigating chambers were weighed before and after the experiment, thus ensuring complete evaporation of the toxicant from the carrier into the chamber. Laboratory temperature was maintained between $30-31^{\circ} \mathrm{C}$. Blank experiments were performed in the same way using only paraffin oil or pentane. Dead insects were separated and kept under observation for a further $24 \mathrm{~h}$. before mortalities were counted. For the calculation of $\mathrm{LC}_{50}$ three doses of each test compound/ mixture were assayed each in three replicates (Table I). Column fractions of the defensive secretion were also assessed for toxicity by the same method and \% mortalities were calculated. Synthetic mixtures of $t$-2-hexenal and $\mathrm{n}$-tridecane with ratios varying from 100:00 $(\mathrm{w} / \mathrm{w}) \longrightarrow 00: 100(\mathrm{w} / \mathrm{w})$ were prepared by the method described earlier. From each mixture, a fixed dose was assayed in three replicates for each test insect species. This dose was equal to double the $\mathrm{LC}_{50}$ value as determined previously in the case of 60:40 mixture of $t$-2-hexenal: n-tridecane (Table 3, Column 2). Thus, doses of $1.20,0.30$ and $0.26 \mathrm{ppm}$ of $t$-2-hexenal and $\mathrm{n}$-tridecane mixture were used for A.longipes, S. cerealella and C. quinquefasciatus respectively (Table 2).

\section{RESULTS}

\section{General characteristics of the defensive secretion}

In response to physical irritation, defensive secretion was ejected as a light coloured liquid with a pungent smell. This was found to be highly volatile, leaving only a trace of liquid on a glass surface. In the presence of these volatiles the other $C$. janus emitted their defensive secretion fairly fast.

\section{Chemical properties}

GLC analysis of the defensive secretion showed the presence of 23 compounds. Two components, $t$-2-hexenal and n-tridecane, characterized by GC-MS and GLC co-injections with authentics made up an average of $90 \%$ (range $87 \%-96 \%$ ) of the volatiles. Lesser compounds also characterized by GC-MS included 4-oxo-t-2-hexenal and dodecane.

A remarkable quantitative and qualitative concordance in the mean compositions of major and minor components was obtained for males and females, except in the case of 4-oxo-t-2-hexenal (Student's t-test $\mathrm{p}<0.05$, Table 4, entries 1-3). Females however, ejected more secretion than males (t-test, $p<0.01$ Table 4 entry 3 ). 
Table 4: Comparative Composition of the Defensive secretion of male and female C. janus

\begin{tabular}{cllllll}
\hline Entry & $\begin{array}{l}\text { Weight \# } \\
\text { per } \\
\text { ejection } \\
(\mathrm{mg})\end{array}$ & $t$-2-hex. & n-tridec. & $\begin{array}{l}\text { 4-oxo-t-2- } \\
\text { hexenal }\end{array}$ & dodec. & $\begin{array}{l}\text { tracer } \\
\text { comp }\end{array}$ \\
\hline $1 \quad(6)$ & $\begin{array}{l}2.74 \\
\mathrm{~N}=15\end{array}$ & $\begin{array}{l}62.80 \% \\
( \pm 0.23)\end{array}$ & $\begin{array}{l}28.06 \% \\
( \pm 1.81)\end{array}$ & $\begin{array}{l}4.33 \% \\
( \pm 0.42)\end{array}$ & $\begin{array}{l}0.64 \% \\
( \pm 0.64)\end{array}$ & $4.1 \%$ \\
$2 \quad(\$)$ & 4.80 & $60.90 \%$ & $29.46 \%$ & $5.70 \%$ & $0.62 \%$ & $3.32 \%$ \\
$\mathrm{~N}=15$ & $( \pm 0.30)$ & $( \pm 2.28)$ & $( \pm 1.70)$ & $\begin{array}{l}( \pm 0.52) \\
( \pm 0.03)\end{array}$ & \\
$3 \mathrm{t}^{* *}$ & 5.28 & 0.65 & 0.63 & 2.17 & 0.13 & \\
28 & 0.01 & n.s & n.s & $<0.05$ & n.s & \\
\hline
\end{tabular}

${ }^{*}$ Calculated from GLC compositions

** Differences in the male and female samples

\# All values represent mean ( \pm S.E. ) of three determinations

\section{Toxic properties}

Fresh defensive secretion:

Preliminary investigations revealed that fresh defensive secretion of one $C$. janus causes immediate death of all test insects $(\mathrm{N}=50$ in each case). It was clear, therefore, that this defensive secretion has to be tested in a diluted form. It was also seen that this property was highly connected to the volatile portion of the secretion because removal of the volatiles caused a great reduction in mortality. The use of non toxic, volatile solvent as the media was thus unsuccessful. Following the method of Peschke and Eisner ${ }^{10}$ finally, paraffin oil was our choice.

High toxicity of this defensive secretion to all test species is well demonstrated by the low LC50 values ranging from $0.002 \mathrm{ppm}$ to $0.197 \mathrm{ppm}$. The comparable value of the commercial insecticides, Malathion and Elsane ranged from $0.000026 \mathrm{ppm}$ to $0.00039 \mathrm{ppm}$ and from 0.000017 to $0.00053 \mathrm{ppm}$ respectively (Table 3). 


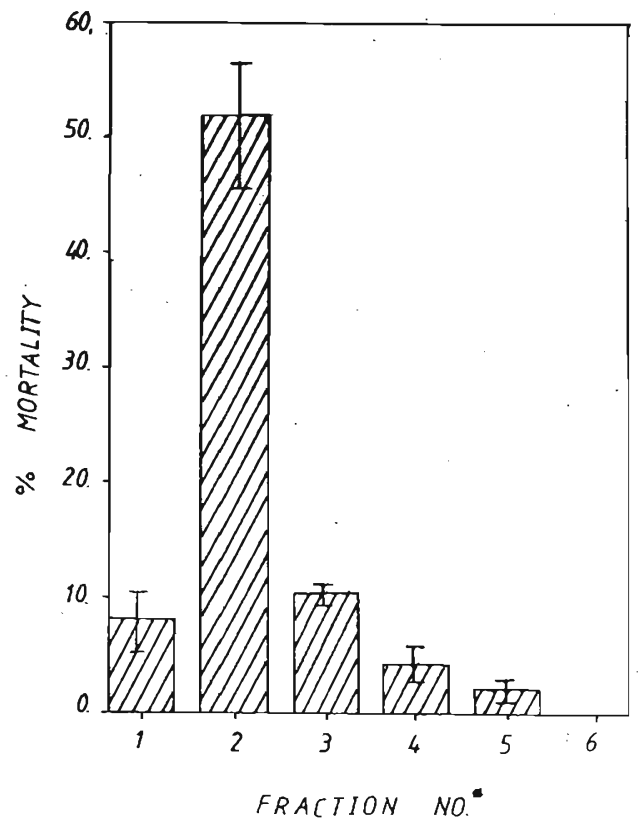

Figure 1. Column fractions of the defensive secretion vs\% mortalities of $A$. longipes

\begin{tabular}{|c|c|c|}
\hline $\begin{array}{l}\text { Combined Fraction } \\
\text { Number \# }\end{array}$ & Composition by GLC & Eluting solvent \\
\hline $\begin{array}{l}1 \\
2\end{array}$ & $\begin{array}{l}\text { Tridecane, dodecane } \\
\text { Tridecane, } t \text {-2-hexenal }\end{array}$ & $\begin{array}{l}\text { petrolelum ether } \\
\text { pet-ether: } \mathrm{CH}_{2} \mathrm{Cl}_{2} \\
\qquad(95: 05)\end{array}$ \\
\hline 3 & $t$-2-hexenal & $\begin{array}{c}\text { pet-ether: } \mathrm{CH}_{2} \mathrm{Cl}_{2} \\
(50: 50)\end{array}$ \\
\hline 4 & $\begin{array}{l}\text { t-2-hexenal, 4-oxo-t- } \\
\text { 2-hexenal }\end{array}$ & $\mathrm{CH}_{2} \mathrm{Cl}_{2}$ \\
\hline 5 & Träcer compounds & $\begin{array}{c}\mathrm{CH}_{2} \mathrm{Cl}_{2}: \mathrm{CH}_{3} \mathrm{OH} \\
(95: 05)\end{array}$ \\
\hline $6^{*}$ & Tracer compounds & $\begin{array}{c}\mathrm{CH}_{2} \mathrm{C1}_{2}: \mathrm{CH}_{3} \mathrm{OH} \\
(50: 50)\end{array}$ \\
\hline
\end{tabular}

Column fractions of similar GLC compositions were combined. A fixed dose of $0.50 \mathrm{ppm}$ from each fraction was assayed with $30 \mathrm{~A}$. longipes. Each histogram is the mean of three replicates. Slanted bars indicate \pm S.E

- This fraction showed no \% mortality 


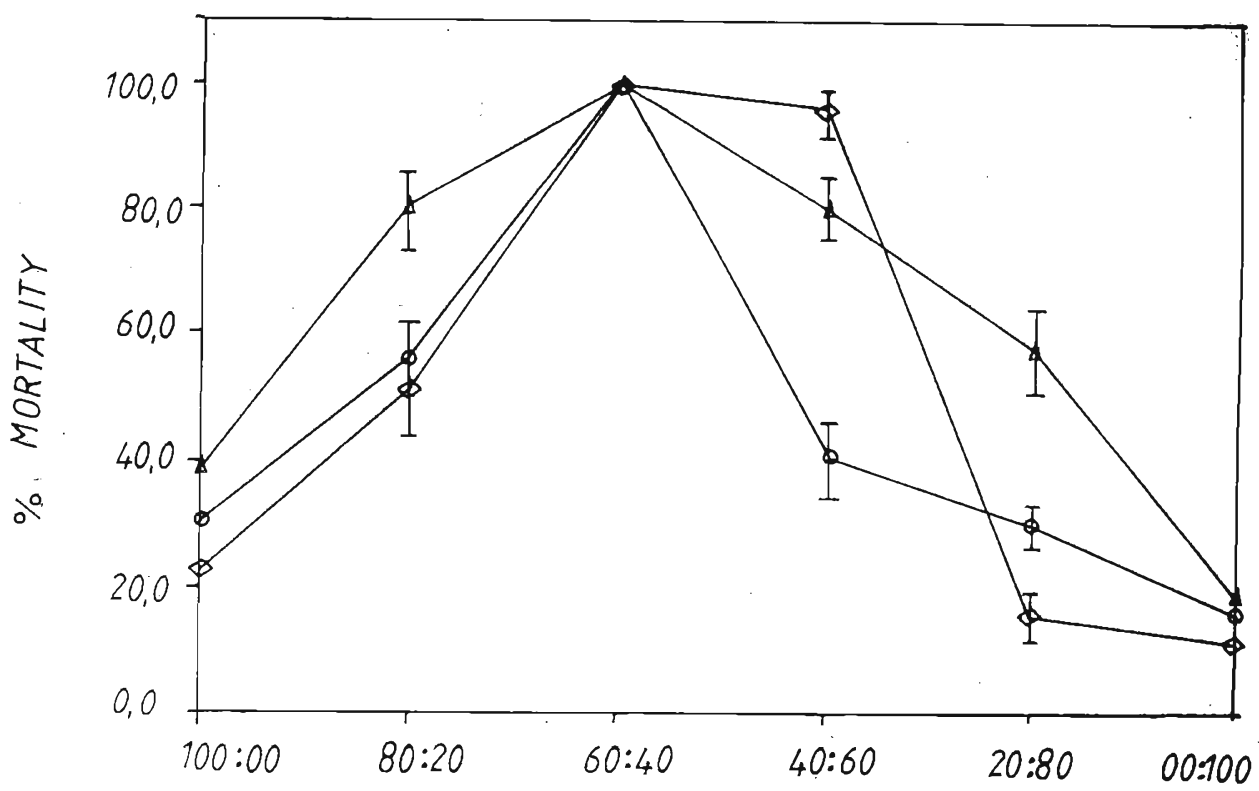

Figure 2: Variation of \% mortalities of $A$. longipes (•)

$S$. cerealella $(\mathrm{O})$ and $C$. quinquefasciatus $(\Delta)$

with different combinations of $\mathbf{t}$-2-hexenal/n-tridecane

* Synthetic samples from Aldrich chemicals: ratios indicate weight ratios of each component: the doses used were fixed for a particular insect species and were $1.20,0.30$ and $0.26 \mathrm{ppm}$ for $A$. longipes, $S$. cerealella and $C$. quinquefasciatus. The number of test insects varied from 20-30. Each point is a mean of three replicates. Verlical bars indicate standard errors of the mean.

\section{Column fractions and synthetic chemicals}

Column fractionation of the defensive secretion followed by GLC analysis led to six major fractions having compositions as indicated in Figure 1 . Preliminary tests indicated considerable toxicity (52\% mortality of $A$. longpipes) only in fraction 2, which consisted mainly of $t-2$ hexenal and tridecane (Figure 1). This led to further bioassay on a series of combinations of the above constituents (synthetic equivalents) as follows: (w/w) 100:00 (Pure hexenal). 80:20, 60:40, 40:60, 20:80, 100 (pure tridecane). The dose used for a particular test species was fixed as indicated in Table 2. It was observed that 2-hexenal is comparatively the more powerful toxicant out of the two constituents showing mortalities of $22 \%, 38 \%$ and $30 \%$ for $A$. longipes $C$. quinquefasciatus and S. cerealella while that of $\mathrm{n}$-tridecane was $11 \%, 18 \%$ and $17 \%$ respectively for the same doses (Figure 2, at 100:00 of $t-2$ hexenal and at 00:100 of tridecane). All combinations of the above two constituents showed higher toxicities and the variation of toxicities with different ratios of constitutents was characteristic of the test species (Figure 2). More interestingly, the combination of $t$-2-hexenal: n-tridecane at the ratio $60: 40(\mathrm{w} / \mathrm{w})$ showed highest toxicity for all three test insects (Figure 2). 
major components as evident from the above study, possible contributions from minor and tracer compounds cannot be excluded. This fact is demonstrated by the higher toxicity of the fresh defensive secretion to all three test insects than those of the synthetic chemical combinations of 2-hexenal and tridecane (Table 3).

In conclusion, high fumigant properties of the defensive secretion of $C$. janus was shown by the above study. From our choice of test insects it was also shown that this secretion is not.specifically formulated against enemies of $C$. janus but also effective against other pests of man. Any practical application of the synthetic mixture should, however, be attempted only through a non volatile derivative of the aldehyde component.

\section{Acknowledgements}

The authors thank International Foundation for Science, Sweden (F/936-1) and the Natural Resources Energy and Science Authority of Sri Lanka (RG/87/B/5) for funding this research, Dr I.V.S. Fernando and Dr Mrs A. Pathiratna of the Dept of Zoology, University of Kelaniya for advice and Dr M.B. Wickramasinghe of the Anti Malaria Campaign for identifying and supplying mosquitoes.

\section{References}

1. Baggini A., Bernard I.R., Casnati G., Pavan M. \& Ricca A. (1966). Defensive secretions in Hemipteran Heteropteran insects. Eos (Madrid) 42:7-26.

2. Blum M.S. (1981). Chemical defense of Arthropods pp. 562. Academic Press, New York.

3. Aldrich J.R. (1988). Chemical Ecology of the Heteroptera. Annual Review of Entomology 33:211-238.

4. Crew R.M., Blum M.S. \& Collingwood C.A. (1972). Comparative Analysis of Alarm Pheromones in the ant genus Crematogaster. Comparative Biochemistry and Physiology 43 B: 703-716.

5. Francke W., Buehring M. \& Horstmann K. (1980). Studies on the pheromones of Formica polyctena. Zeitschrift fur. Naturforschung 35 c: 829-831.

6. Loefquist J. \& Bergstroem G. (1980). Volatile communication substance Dufour gland of virgin female and old queen of the ant Formica polyctena. Joumal of Chemical Ecology 6:309-320.

7. Taketoshi I. (1974). The scent of stink bugs (Hemiptera: Pentatomidae). Applied Entomology and Zoology 9:153-158.

8. Blum M.S. (1985). Alarm pheromones. Comprehensive Insect Physiology. Biochemistry and Pharmocology, pp. 193-224 Pergamon Oxford. 
9. Blum M.S. (1964). Insect defensive secretions: Hex-2-enal-1 in Pelmatosilpha coriacea and its repellent values under natural conditions. Annals of the Entomological Society of America 57:600-602.

10. Peschke K. \& Eistner T. (1987). Defensive secretion of the tenebrionid beetle. Blaps mucronata: Physical and chemical determinants of effectiveness. Journal of Comparative Physiology A.161:377-378.

11. Roth L.M. Niegisch W.D. \& Stahl W.H. (1956). Occurence of 2-hexenal in the cockroach. Eurycotis floridana. Science 123:670-1.

12. Remold H. (1963). Scent glands of land bugs, their physiology and biological function. Nature 198:764-768.

13. Gunawardena N.E. \& Ranatunga P.R. (1987). Major volatiles of the defensive secretion of Coridius janus (Pentatomidae). Proceedings of Sri Lanka Association for the Advancement of Science 43:212.

14. Kathuria O.P., Brown W.V. \& Gilby A.R. (1975). The defense secretion of Apongopus janus (Fabricius). Hemiptera: Pentatomidae. Indian Journal of Entomology 36:31-33.

15. Tsuyri T., Ogata Y., Yamamoto I. \& Shimi K. (1965). Stink bug aldehydes, Agricultural Biological Chemistry 29:19-27.

16. Preswitch G.D. (1976). Compositions of scents of eight EastAfrican Hemipterans. Nymp-adult chemical polymorphism in Coreids. Annals of the Entomological Society of America 69:812-814.

17. Dateo G. P. \& Roth L.M. (1967). Occurence of gluconic acid and 2-hexenal in the defensive secretion of three species of Eurycotis (Blattaria: Blattidae: Polyzosteriinae) Annals of the Entomological Society of America 69:1025-1030

18. Lockwood J. H. \& Story R.N. (1985). Bifunctional pheromone in the first instar of the southern green stink bug. Nazara viridula L. (Hemiptera: Pentatomidae) and its characterization and interaction with other stimuli. Annals of the Entomological Society of America 78:74-79.

19. Eisner T., Meinwald Y.C.M., Algop D.W. \& Carrel J.E. (1968). Defence mechanisms of arthropods: XXl Formic acids and n-nonyl acetate in the defensive spray of species of Hellumorphoids. Annals of the Entomological Society of America 61: 610-613.

20. Weatherston J. (1967). The chemistry of arthropod defence substance. Quarterly Review 21:287-300. 